\title{
Atorvastatin Induced Vasculitis
}

\author{
Prasad $\mathbf{T}^{* 1}$, Kalaiselvan $\mathbf{V}^{2}$, Surabhi $\mathbf{S}^{3}$, Vivek $\mathrm{D}^{4}$, Ranvirkumar $\mathbf{S}^{5}$ and Gyanendra Nath $\mathbf{S}^{6}$ \\ ${ }^{1}$ Scientific Assistant, ${ }^{2}$ Principal Scientific Officer, ${ }^{3,4,5}$ Technical Associtae, ${ }^{6}$ Secretary-cum-Scientific Director, National \\ Coordination Centre-Pharmacovigilance Programme of India, Indian Pharmacopoeia Commission, Sector-23, Raj Nagar Ghaziabad, \\ Uttar Pradesh -201002
}

\begin{abstract}
Adverse drug reactions are regarded as an important public health problem as they may be potentially lifethreatening. The World Health Organization defines Adverse drug reaction (Adverse Drug Reaction) as a response to a drug which is noxious, unintended, which occurs at doses normally used in human for prophylaxis or diagnosis of a disease or for modification of physiological function. We report two adverse drug reaction case reports. Case 1: A forty six years old Indian female adult developed Vasculitis over both legs and back after four months. Patient was prescribed Tablet Atorvastatin $20 \mathrm{mg}$, Tablet Atenolol $25 \mathrm{mg}$, Tablet Levothyroxine sodium $100 \mathrm{mg}$ and Tablet Acetylsalicylic acid $100 \mathrm{mg}$. Patient had been treated with methylprednisolone and azathioprine. Case 2: A fifty six years old Indian female adult had been treated with Atorvastatin $10 \mathrm{mg}$, Telmisartan $40 \mathrm{mg}$ and Zolpidem $10 \mathrm{mg}$ for essential hypertension. Patient had been treated with methylprednisolone. Hence there is a need for awareness of the adverse events related to statins therapy to avoid life-threatening complications.
\end{abstract}

Keywords: Pharmacovigilance, Adverse Drug Reaction, Atorvastatin, Vasculitis, Suspected Unexpected Serious ADR (SUSAR)

\section{INTRODUCTION}

Medicines are used to treat illnesses as they have the ability to modify the altered physiological process in the body. But at the same time, due to various predisposing factors, drugs always pose certain amount of risk in the form of unwanted or unintended effects known as adverse drug reactions (ADRs). ${ }^{1}$ Adverse drug reactions are regarded as animportant public health problem as they may be potentially life-threatening. The World Health Organization defines Adverse drug reaction (ADR) as a response to a drug which is noxious, unintended, which occurs at doses normally used in human for prophylaxis or diagnosis of a disease or for modification of physiological function. The typical pharmacological classification of ADRs by Rawlins and Thompson²separates these into two major sub types: Type A reactions, which are dose dependent and predictable, and Type B reactions which are not dose dependent and unpredictable. The majority of ADRs are Type A reactions. Type B reactions comprise approximately $10-15 \%$ of all ADRs and include hypersensitivity drug reactions. ADRs are regarded as the one of the leading causes of increased health care cost, morbidity and mortality. ${ }^{3}$

Vasculitis is a condition that involves inflammation of the blood vessels and can affect any of the body's blood vessels including arteries, veins, and capillaries. If a blood vessel is inflamed, it can narrow or close off; rarely the blood vessel will stretch and weaken, causing it to bulge. This bulge is known as an aneurysm. Inflammation can be short-term (acute) or long-term (chronic) and can be so severe that the tissues and organs supplied by the affected vessels do not get enough blood. The shortage of blood can result in organ and tissue damage, even death. ${ }^{4}$
Submitted Date : 25-04-2014 Accepted Date : 12-09-2014

DOI: 10.5530/ijopp.7.3.13

Address for correspondence: Dr. Prasad Thota Scientific Assistant, National Coordination Centre-Pharmacovigilance Programme of India, Indian. Pharmacopoeia Commission, Ghaziabad, Uttar Pradesh-201002, India E-mail: prasad.thota187@ gmail.com

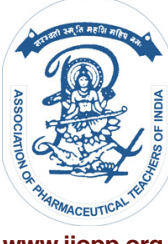

www.ijopp.org 
Drug induced Vasculitis is the inflammation of blood vessels caused by the use of various pharmaceutical agents including antibiotics, Thiazide diuretics, Thiouracil, oral anticoagulants such as warfarin and coumarin, Non-Steroidal Anti-Inflammatory Drugs (NSAIDs). ${ }^{5}$

Statins are the most effective and best tolerated agents for treating dyslipidemia. These drugs are competitive inhibitors of 3-hydroxy-3-methylglutaryl coenzyme A (HMG-CoA) reductase, which catalyse the early, ratelimiting step in cholesterol biosynthesis. ${ }^{6}$ Statins are well tolerated and have very few side-effects. Adverse reactions include photo sensitivity, hepatotoxicity, myopathy and muscle weakness. A rare hype sensitivity syndrome has been reported which is characterized by at least one of the following features: anaphylaxis, angioedema, lupus erythematosus-like syndrome, ploymyalgia theumatic, Vasculitis, purpura, thrombocytopenia, leukopenia, haemolytic anaemia, toxic epidermal necrolysis and dermatomyositis. ${ }^{7}$ Atorvastatin is frequently prescribed among statins with initial dose of $10 \mathrm{mg}$ daily, may be adjusted at intervals of 4 weeks up to a maximum of 80 $\mathrm{mg}$ daily. ${ }^{8}$ Recently, some cases of statin-induced Vasculitis have been reported. In this study, we report two cases of Vasculitis probably induced by atorvastatin.

\section{MATERIAL AND METHODS}

National Coordination Centre-Indian Pharmacopoeia Commission (IPC) collects the spontaneous adverse drug reaction reports/ Individual Case Safety Reports from its member regional centres or ADRs Monitoring Centres under the Pharmacovigilance Programme of India (PvPI). The reports submitted to IPC through VigiFlow (ICSRs Management system) have been stored in global ICSRs database i.e. VigiBase ${ }^{\mathrm{TM}}$. The two cases were identified during the signal generation from the VigiBase $^{\mathrm{TM}}$.

\section{CASE NO: 1}

A 46-year old man presented with fever and rashes over both legs and back. The patient was a known case of hyperlipidemia and was prescribed with tablet atorvastatin $20 \mathrm{mg}$ for last 4 months. He was also taking atenolol $25 \mathrm{mg}$ and acetylsalicyclic acid $100 \mathrm{mg}$ for hypertension and levothyroxine $100 \mathrm{mg}$ for hypothyroidism. The patient was diagnosed as a case of Vasculitis and hospitalized. Patient was treated with methylprednisolone and azathioprine and the outcome was recovering.

\section{CASE NO: 2}

A 56-years old Indian female adult was treated with Atorvastatin $10 \mathrm{mg}$, Telmisartan $40 \mathrm{mg}$ and Zolpidem
$10 \mathrm{mg}$ for essential hypertension. She complained of rashes over back and right hand and later on diagnosed as a case of Vasculitis. Patient was treated with methylprednisolone.

\section{DISCUSSION}

Statins are considered well-tolerated lipid-lowering agents with an excellent safety profile and therapeutic range. Their effects have been an area of intense research to show additional benefits of these lipid-lowering agents. ${ }^{9}$ Patel et al discuss how statins, even at high doses, provide an effective decrease in LDL and even promote anti-inflammatory effects within atherosclerotic plaques. ${ }^{10}$

We are now reporting two cases of vasculitits induced by atorvastatin. Complete resolution of symptoms occurred with administration of a tapering dose of steroids. Causality assessment of the adverse drug event (ADE) was carried out using WHO-UMC criteria and Naranjo's Scale. In both the cases, the patient improved on providing the treatment. However data on the challenge (withdrawal of the drug) is unclear. Hence, the ADE was possibly caused by atorvastatin (WHO-UMC criteria: Possible; Naranjo's Score: 4, possible). The severity of the reaction was moderate in nature (modified Hartwig and Siegel's Scale), ${ }^{11}$ and it was definitely preventable (modified Schumock and Thornton criteria). ${ }^{12}$

Haroon et al reported a similar case of ANCA-associated systemic Vasculitis that was induced by atorvastatin. ${ }^{13}$ In a study it was reported that among 54 reports from FDA $0.04 \%$ have Leukocytoclastic Vasculitis associated with use of atorvastatin. ${ }^{14}$ In a study comparing the values of Common Carotid Artery (CCA), Intima-Media Thickness (IMT) to the incidence of stroke, Myocardial Infarction (MI) and death in patients with Takayasu's Arteritis (TA), it was reported that CCA-IMT is increased in TA and regression of IMT is possible with immunosuppressive treatment and atorvastatin. ${ }^{15}$ Alissa $S$ et al reported a case of ANCA-associated systemic Vasculitis that was induced by simvastatin. ${ }^{16}$

\section{CONCLUSION}

Statins are frequently prescribed for a variety of indications such as diabetes mellitus, ischemic heart disease, hypertension, cerebrovascular diseases. Hence there is a need for awareness of the adverse events related to statins therapy to avoid life-threatening complications.

\section{ACKNOWLEDGEMENTS}

Indian Journal of Pharmacy Practice, Vol 7, Issue 3, Jul-Sep, 2014 
We take this golden opportunity to express our thanks to Dr. Suparna Chaterji, Head Department of Pharmacology, Institute of Post Graduation Medical Education and Research, Kolkata \& Dr. N. Saralan, Department of Pharmacology, SDU Medical college, Kollar, for identifying, collecting, monitoring \& reporting of these suspected unexpected serious ADR cases to Indian patients drug safety monitoring database i.e. Vigi Flow $\&$ continuous encouragement of PvPI.

\section{CONFLICTS OF INTEREST}

The authors declare that no conflict of interest and there this study was not funded.

\section{REFERENCES}

1. Parthasarathi G, Olsson S. Adverse drug reactions- A text book of clinical pharmacy practice. Orient long man. 2004; 8: 84-6.

2. Eva Rebelo, Gomes, Pascal Demoly. Epidemiology of Hypersensitivity Drug Reactions. Current Opinion on Allergy Clinical Immunology. 2005; 5(4): 309-16.

3. Prima BS, Guetz CM, Rinh TL, olsky M. Drug related emergency department visits and hospitals admissios. American Journal of hospital pharmacy. 1992; 49(7): 1696-700.

4. Radic M, Martinovic Kaliterna D, Radic J. Drug-induced Vasculitis: a clinical and pathological review. Neth J Med. 2012 Jan; 70(1): 7-12.
5. www.dermnetnz.org/vascular/vasculitis. Cited on 2013 April 29.

6. Goodman, Gliman's. The pharmacological basis of therapeutics. Tenth edition McGraw Hills; 2001. p. 984-9.

7. Gerald K. Pharmacist's drug hand book. Springhouse Corporation; 2001. P. 46.

8. Martindale. The Complete Drug Reference. Thirty Third Edition. Pharmaceutical Press; 2002. P. 842-3.

9. Liu PY, Liu YW, Lin LJ, et al. Evidence for statin pleiotropy in humans: Differential effects of statins and ezetimibe on rho-associated coiled-coil containing protein kinase activity, endothelial function, and inflammation. Circulation. 2009; 119(1): 131-8.

10. Patel TN, Shishenbor MH, Bhatt DL. A review of high dose statin therapy; targeting cholesterol and inflammation in atherosclerosis. European Heart Journal. 2007; 28(6): 664-72.

11. Hartwig SC, Siegel J, Schneider PJ. Preventability and severity assessment in reporting adverse drug reactions. American Journal of Hosp Pharmacy. 1992 Sep; 49(9): 2229-32.

12. Schumock GT, Thornton JP. Focusing on preventability of adverse drug reactions. Hospital Pharmacy. 1992; 27(6): 538.

13. Haroon M, Devlin J. A case of ANCA-associated systemic Vasculitis induced by atorvastatin. Clinical Rheumatology. 2008; 27(2): S75-7.

14. www.ehealthme.com/ds/lipitor/leukocytoclastic+vasculitis. Cited on 2013 April 30.

15. Sivakumar MR, Sivakumar S. Intima media thickness in takayasu arteritis and change with treatment. Oxford J Rheumatology. 2010; 49(1): 234.

16. Alissa S, Brotman O'Neill DO, Jausheng Tzeng MD, Herbert Dardik MD. Simvastatin-induced Vasculitis with secondary mesenteric ischemia and intestinal infarction. Vascular disease management 2010;7:E148-E149. 